\title{
Predicting impact of climate change on habitat suitability of guava fruit fly, Bactrocera correcta (Bezzi) using MaxEnt modeling in India
}

\section{JAIPAL S. CHOUDHARY ${ }^{1^{*}}$, MADHUMITA KUMARI ${ }^{1}$, SANTOSH S. MALI ${ }^{1}$, MAHESH K. DHAKAR ${ }^{1}$, BIKASH DAS ${ }^{1}$, ARUN K. SINGH ${ }^{1}$ and BHAGWATI P. BHATT ${ }^{2}$}

\author{
${ }^{1}$ ICAR Research Complex for Eastern Region, Research Centre, Plandu, Ranchi-834010 (Jharkhand) India. \\ ${ }^{2} I C A R$ Research Complex for Eastern Region, BVC, Parishar, Patna-800014 (Bihar) India. \\ *Corresponding Author: Email: choudhary.jaipal@gmail.com
}

\begin{abstract}
Maximum entropy (MaxEnt) modeling was used to predict impact of climate change on habitat suitability of guava fruit fly, Bactrocera correcta in India. It is a polyphagus pest on a wide variety of fruit crops. Future prediction of potential habitat of B.correcta was done for the year 2050 and 2070 with RCP 2.6, RCP 4.5, RCP 6.0 and RCP 8.5 climate scenarios. The model preformed better than random with an average test AUC value of 0.75 of 100 replicate tests run. Under the present and future climatic conditions, the model predicted high habitat suitable category for $B$. correcta in the areas of south-western coastal (Kerala, Karnataka, Tamilnadu, Maharashtra and Gujarat) part of India by 2050 and 2070. Presently absolute unsuitable areas of Indian sub-continent are projected to be slightly suitable for $B$. correcta by 2070 due to increase in temperature coupled with decrease in cold stress. The predictive modeling approach presented here provides an outline for future risk of B.correcta in India under climate change scenarios, which can be used for its better management strategies.
\end{abstract}

Keywords : Species distribution modeling; Bactrocera correcta; climate change; maximum entropy modeling

It is universally accepted fact that climate change is a significant driver for changing insect pests status as it may affect insect species distribution, abundance, habitat suitability, rate of invasion and increase outbreak frequencies (Berzitis et al., 2014; Choudhary et al., 2017). Tephritidae is one of the major economic important family of Dacine fruit flies. Dacine fruit flies are distributed across the entire world and are predominant in the tropical and subtropical areas. Being the world's largest producer of tropical and subtropical fruits, India suffers a great loss due to fruit flies in crops like mango, guava, peach, pear, apricot, sapota, citrus, jujube, cucurbits, etc. also as the infection of fruit flies restrict the export of these fruits. Bactrocera species viz., B. dorsalis (Hendel), B. zonata (Saunders) and $B$. correcta (Bezzi) are considered to cause maximum damage in fruit crops. These three species form dorsalis-zonatacorrecta complex, which is one of the vital fruit fly pest complexes in India (Kapoor, 2002).

B. correcta was first recorded in 1916 from Bihar state of India and is now, spread rapidly throughout countries of south East Asia, including Pakistan, Nepal, Burma, Thailand, Sri Lanka, Vietnam and China (Drew and Raghu, 2002). B. correcta is also indexed as a quarantine pest by a number of countries worldwide (White and Elson-Harris,
1992). The problem of its management is becoming more complex due to the remarkable rapid spread and number of available hosts plants in India. As other fruit flies species, distribution and abundance of $B$. correcta are also highly influenced by climatic factors (temperature, moisture, humidity and their seasonal variation), especially the effect of temperature, which play very important role in development, reproduction and survival (Babu and Viraktamath, 2003). Since, this species have a direct impact on Indian economy, and the risk of this species being established thus information regarding suitable habitat and the influence of climatic factors on population build up is necessary for its effective management.

\section{MATERIALS AND METHODS}

\section{Occurrence data records}

Geographic co-ordinates (latitude and longitude) of the particular location where the species was found are used for species distribution modeling and ecological niche models. Occurrence data were collected from the published literature and field surveys. Within a state and then in a district we searched for different locations or co-ordinates. Finally, 70 unique records were used after removing the 
duplicates to generate a primarymap of potential distribution for $B$. correcta.

\section{Climatic data}

For the current climatic condition, we obtained 19 bioclimatic variables from WorldClim database (http:// www.worldclim.org) approx. $\sim 4.6 \mathrm{~km}$ resolution at the equator (2.5 arc $\mathrm{min}$ ). Multicollinearity among environmental variables which obstruct the analysis of species-environment relationships was assessed using ENMTools version 1.0 (Warren et al., 2010). We evaluated pairwise correlation among these variables and generated set of variables with Pearson correlation coefficient having value more than $|\mathrm{r}| \geq$ 0.85. Following ten variables were finalized after multicollinearity for present model;

1. annual mean temperature (Bio1),

2. mean diurnal range (Bio2),

3. isothermality (Bio3),

4. temperature seasonality (Bio4),

5. annual precipitation (Bio12),

6. precipitation of wettest month (Bio13),

7. precipitation of driest month (Bio14),

8. precipitation seasonality (Bio15),

9. precipitation of warmest quarter (Bio18) and

10. the precipitation of coldest quarter (Bio19).

Future climate scenario data for year 2050 and 2070 were downloaded from the World Climate Database, version 1.4 (http://www.worldclim.org/) at a spatial resolution of 2.5 arc minutes on a global scale based on Hadley Global Environment Model 2-Atmosphere Ocean (HADGEM2-AO). These future climate projections are based on fifth assessment of the Intergovernmental Panel for Climate Change $\left(\mathrm{CMIP}_{5}\right)$ and were calibrated and statistically downscaled using the data for 'current' conditions. To reduce the uncertainty in climatic variations, we used data from all four representative concentration pathways (RCPs) i.e. RCP 2.6, RCP 4.5, RCP 6.0 and RCP 8.5. We ran separate models for $B$. correcta using future climate data from all the RCPs.

\section{Modeling procedure}

We used maximum entropy modeling (MaxEnt version 3.3.3; Phillips et al., 2006; http://www.cs.princeton.edu/ wschapire/maxent/), a machine learning algorithm for estimating potential geographic distribution of B. correcta due to its better performance using explicit "regularization" mechanisms even at small sample size as compared to other models (Elith et al., 2006). It requires presence-only data and prediction is prepared based on the theory of maximum entropy of species. Details about MaxEnt performance and initial set up are available in Phillips et al., (2006).

We have used 'replication method' and sub sampling for validation of model and to reduce errors that may occur from the random splitting of data into test and training subsets. In this way, one hundred replicates were run till the end and performance of the model were evaluated by calculating average AUC values for training and test data sets. Jackknife test and per cent variable contribution were utilized to explore the importance of different bioclimatic predictors. To randomization of collected data, we generated a Kernel Density Estimator(KDE) surface following Elith et al. (2006) to draw 10,000 random background points in Maxent.

The performance of the final MaxEnt model was evaluated by using area under receiver operating characteristic (ROC) curve or AUC, which is a threshold independent. We have done jackknife test which allows exploring the contribution of environmental variables by indicating the change in model fit or performance when sequentially with holding each other predictor and refitting models.

Possibilities of flawed predictions of suitable habitat were removed using 'fade-by-clamping'. For estimating current and future occurrence of B. correcta in India, we projected the final MaxEnt model onto spatial data for each of the climate scenarios. Model predictions of each location were imported to geographic information system (GIS) and maps were generated using ArcMap. Four approximate categories, low $(<0.265)$, mild $(0.265-0.4)$, moderate $(0.4$ $0.6)$ and high (0.6-1) of $B$. correcta occurrence at current and future scenarios were defined based on the predicted habitat suitability.

\section{RESULTS AND DISCUSSION}

Models for B. correcta performed better than random, with an average AUC 0.753 over 100 replicate tests run. The current distribution of $B$. correcta was largely affected by the temperature variables followed by precipitation (Fig. 1). The most important variable was temperature seasonality with $56.61 \pm 1.49$ per cent contribution to the MaxEnt model for prediction (Fig. 1). Jackknife test also revealed that temperature seasonality (Bio4), precipitation of driest month (Bio14) and annual precipitation (Bio12) were the strongest contributors for prediction. Information from average sample 


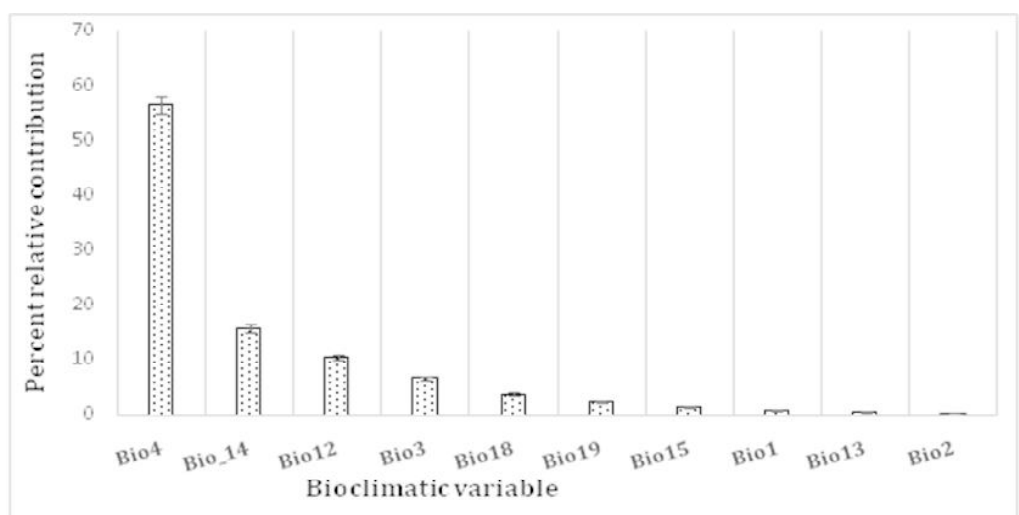

Fig. 1: The relative importance of different bioclimatic variables to MaxEnt model for B. correcta. Relative contributions percent are averages over 100 replicate runs.
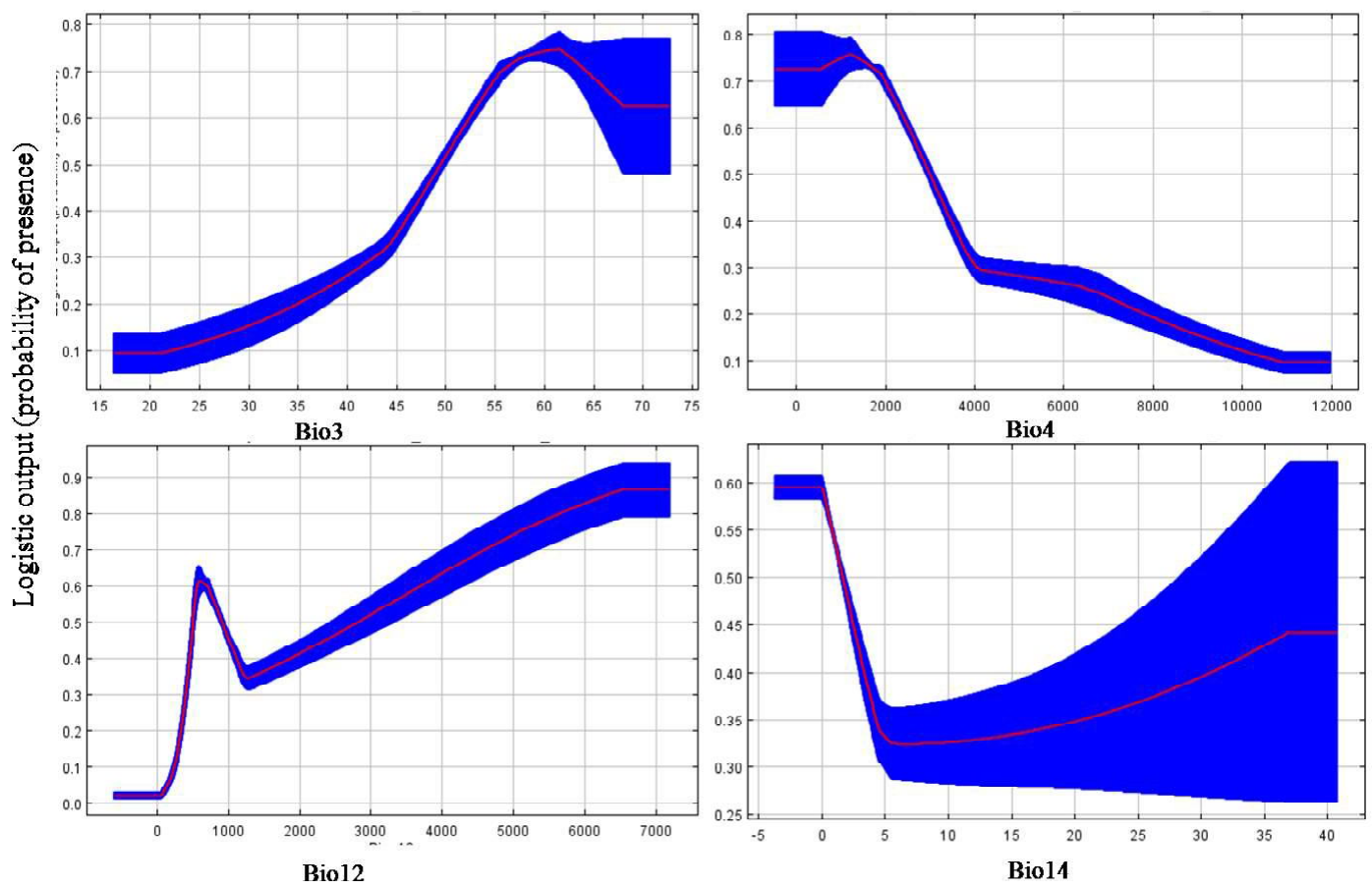

Fig. 2: Relationships between crest four bioclimatic variables and the probability of presence of $B$. correcta in India. The curves line show the mean response and shades are \pm SD calculated over 100 replicates.

value of each top environmental variable was obtained from response curves (Fig. 2). Different bioclimatic variables and their respective response curve showed that the expected occurrence of $B$. correcta was positively correlated with annual precipitation (Bio3) (Fig. 2) where probability of its presence increases with increase in annual precipitation. Possibility of $B$. correcta occurrence decreased with temperature seasonality (Bio4). It shows similar trend with precipitation of driest month (Bio14) but slowly increases after a value of 5 .
The MaxEnt model suggested that the risk of $B$. correcta infestation was very high $(>0.6)$ in southwestern region of India while the majority of the area of central India (Madhya Pradesh, Chattisgarh, Odisha and Rajasthan) showed low to mild infestation under current climatic conditions (Fig. 3). Part of northern India (Part of Uttar Pradesh, Punjab, Haryana and Himachal Pradesh) showed mild (0.265-0.400) infestation except some of the area which are moderate infestestation (0.400-0.600). Extreme eastern and northern India with western region of Rajasthan 


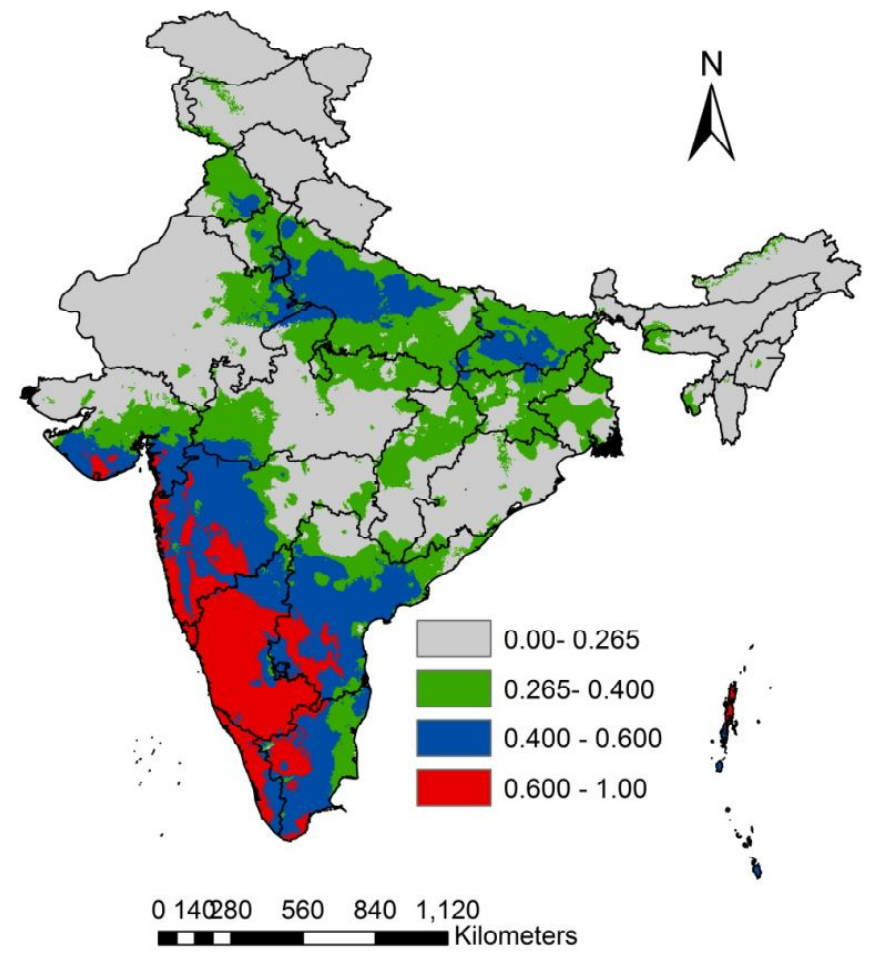

Fig. 3: Current distribution map of B. correcta in India based on current climate variables using MAXENT model.

showed no to very low infestation of $B$. correcta during current distribution.

\section{Climate change impact on habitat suitability}

Model predicted the changes in distribution map of B. correcta in India during 2050, based on HADGEM2-AO GCM model among all RCPs $(2.6,4.5,6.0$ and 8.5) climate scenarios and depicted in Fig. 4. The geographic extent of $B$. correcta occurrence is projected to increase with decreasing the intensity of infestation by 2050 in all climate scenarios. Model projection revealed that, its infestation may increase mild in the states of Odisha, Maharashtra and Gujarat by 2050 . On the other hand, south- western states remains in to high risk category as its area of infestation was almost similar under all the scenarios of RCP 2.6, RCP 4.5, RCP 6.00 and RCP 8.5. In contrast to this, extreme eastern and northern India showed no/low infestation by 2050 . Projected highest changes in risk category over current distribution demonstrated in part of Punjab, Bihar and Jharkhand by 2050.

As century progress to year 2070 , the projected area of suitability is slightly increased to the present (Fig. 5). However, a little difference was observed in the current and projected locations of different states. In south-western
India future predictions showed that extent of suitability range slightly increase by 2050 under the RCP 4.5 and RCP 6.00 scenarios. In this same region, increase in habitat suitability was again observed by 2070 and the moderately infested category is projected to high risk (>0.600) by 2070 . The expansion of high risk category was predicted in the currently moderately affected region of (Andhra Pradesh, Maharashtra and Gujarat) and area of suitability of $B$. correcta increases moderately in Uttar Pradesh, Bihar and Jharkhand (Fig. 5B and 5D) by 2070. For each time period, extreme eastern, extreme northern and western Rajsthan of India are not suitable zone for $B$. correct $a$ and are free from B. correcta under climate scenarios of RCP $2.6, \mathrm{RCP} 4.5, \mathrm{RCP}$ 6.00 and RCP 8.5 (Fig. 4, Fig. 5). In advancement of habitat suitability, currently unsuitable part of north-eastern (Mizoram) India is likely to be suitable for B. correcta by 2070 under RCP 4.5 and RCP 6.0 scenarios and part of Assam and Tripura under RCP 2.6 and RCP 8.5.

The present model was highly successful in predicting B. correcta occurrence. In previous studies MaxEnt model was successfully used for modeling of species geographic distribution (Philips et al., 2006), predicting suitable habitat of endangered tree (Kumar and Stohlgren, 2009), for ecological niche modeling (Warren and Seifert, 2011) and field validation of invasive species (West et al., 2016). Present study in regards to future distribution of $B$. correcta using Maxent modeling suggests that geographic area would increase with decrease extent of suitability in highly suitable area at present under predicted levels of climate change.

Climate is the crucial source for determining the geographic distribution of any organism including $B$. correcta (Sharma et al., 2015; Dalal and Arora, 2016). B. correcta distribution and habitat suitability are highly influenced by isothermality, annual precipitation and temperature seasonality based on present study of species modeling. Previous reports also showed that temperature and precipitation plays a remarkable role in development and distribution of B. correcta (Sarada et al., 2001). For example, Singh and Sharma (2013) also reported that in Ludhiana (Punjab) B. correcta population build up was negatively correlated with rainfall and temperature. This is clear that occurrence and population dynamics of $B$. correcta found to diverse influence by changes in climatic zones even with same weather events (Singh, 2004; Ravikumar, 2005; Vanitha et al., 2017).

Though the current and future potential distributions 

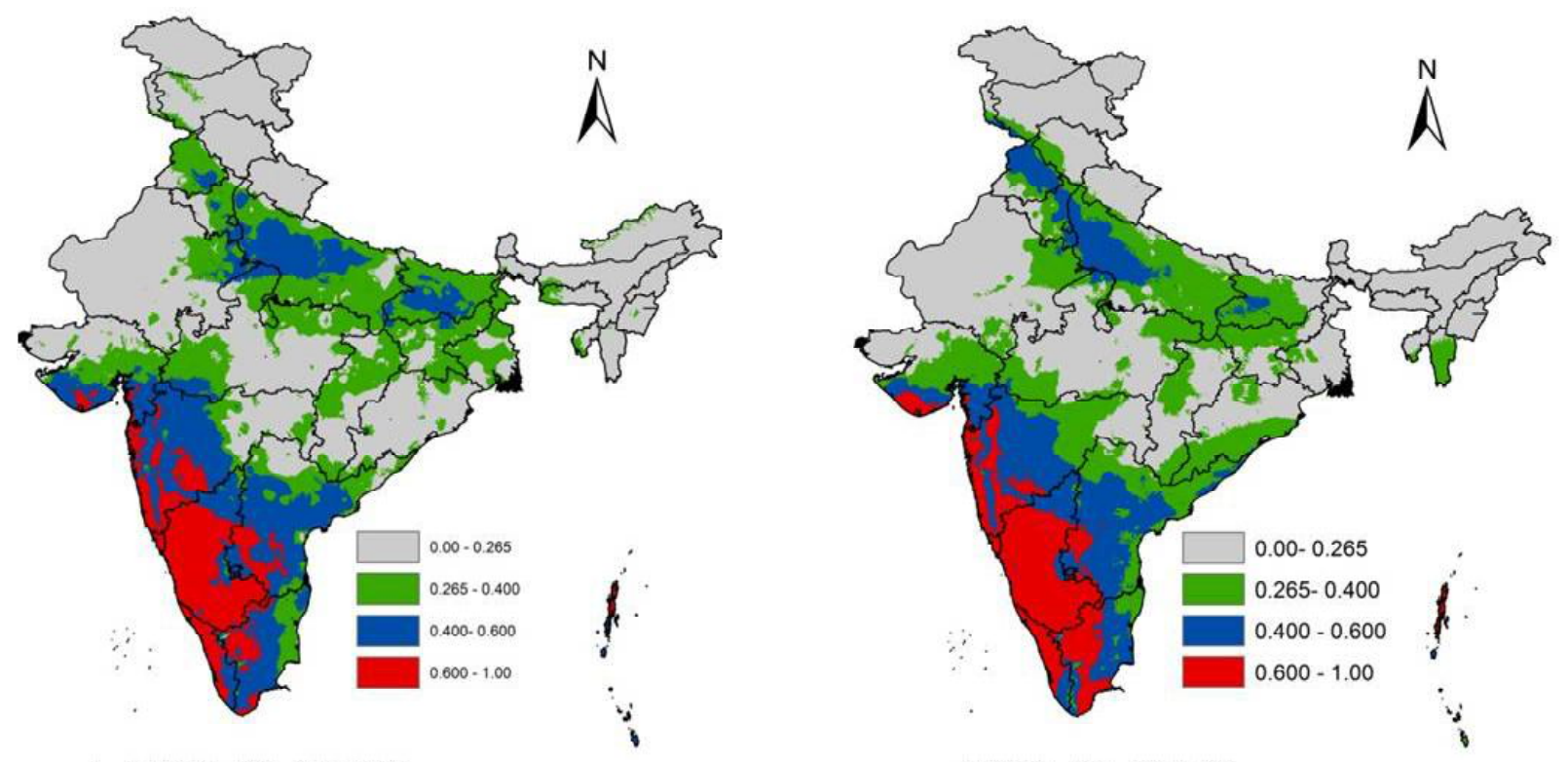

A $\begin{array}{llll}0140280 & 560 & 840 & 1,120 \\ \text { Kilometers }\end{array}$
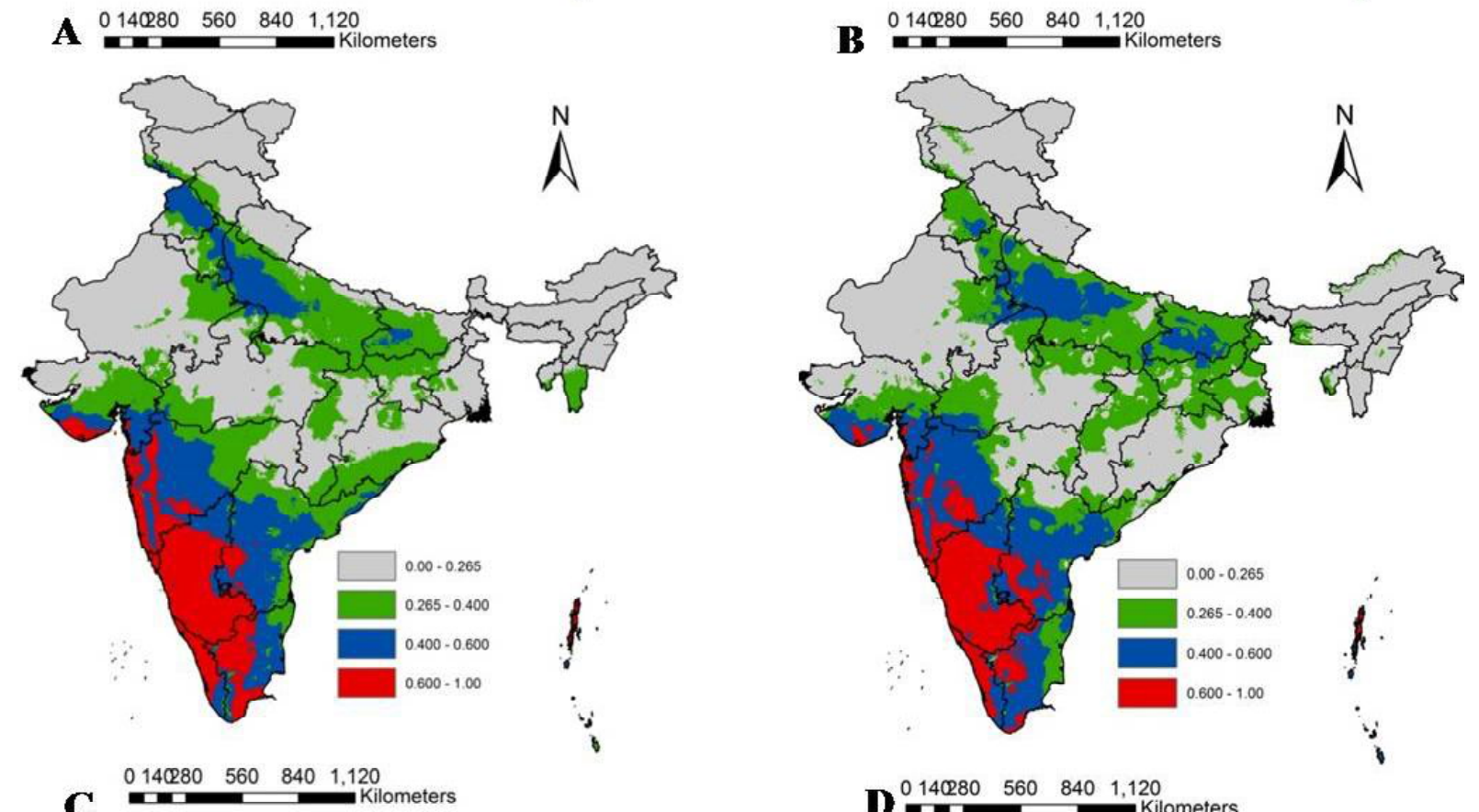

Fig. 4: Projected changes in distribution map of B. correcta in India during 2050, based on HADGEM2-AO GCM model among RCP 2.6 (A), RCP 4.5 (B), RCP 6.0 (C) and RCP 8.5 (D) climate scenarios.

of C. eutraphera were logically predicted by the present study, there are a few factors that limit the precision of the prediction in our work. This may occurs due to many reasons including small number of occurrence records, low resolution predictor data, selection of highly correlated bioclimatic variables, area covered under study, parameterization of model etc. (Sultana et al., 2017). Problem of limited number of occurrence data in present study was overcome by model itself which is robust to small sample size (Philips et al., 2006). Spatial autocorrelation was examined by providing geographic co-ordinates of locations before modeling.

Results of present study could not be possible to compare with published literature due to absence of projections based study in India on $B$. correcta. Present study is the first attempt to understand the $B$. correcta distribution and habitat suitability in India under the changing climate scenarios. Future modeling efforts for $B$. correcta distribution should include a new set of high 

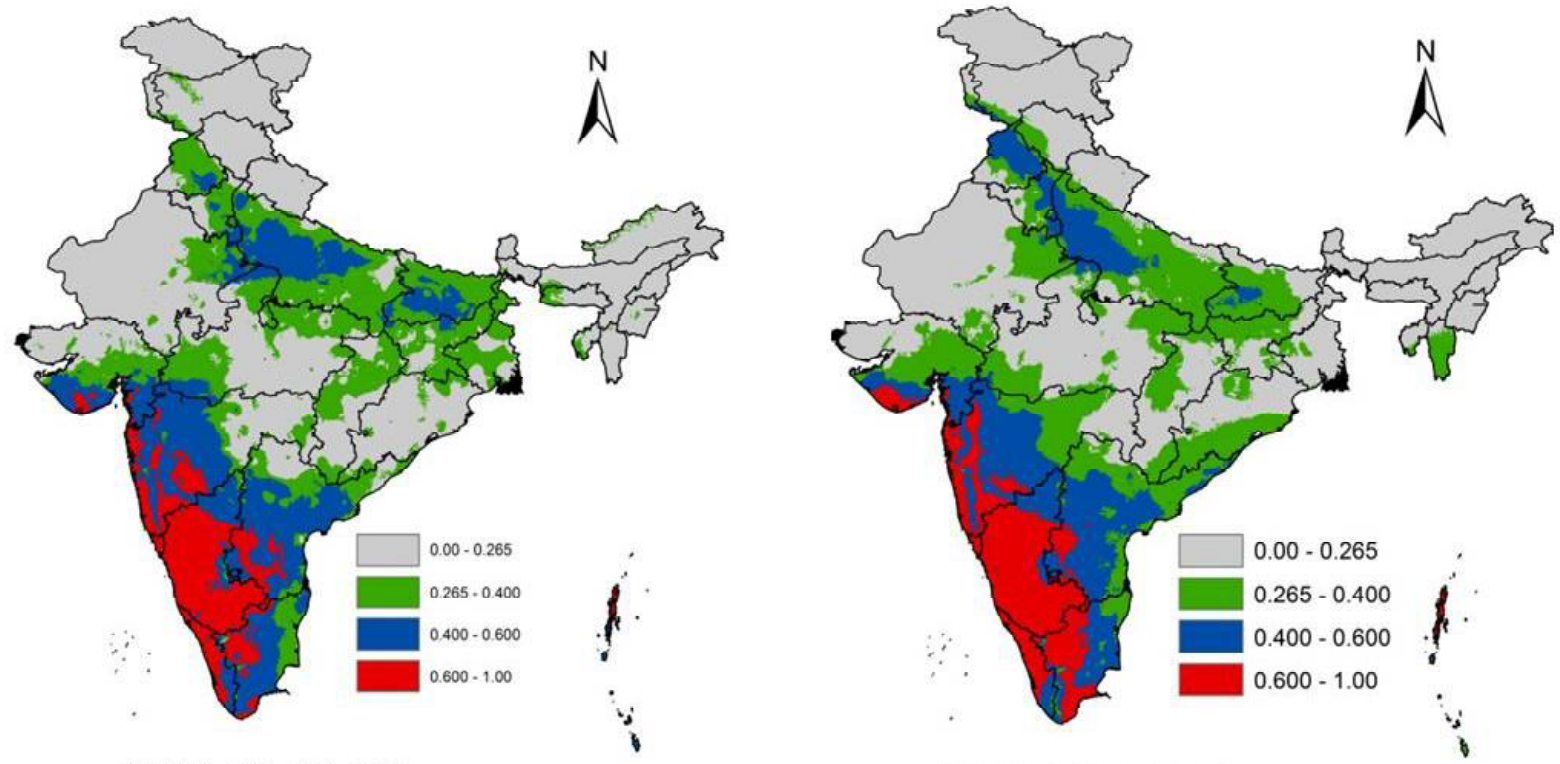

A $\quad 0140280 \quad 560 \quad 840 \quad 1,120$
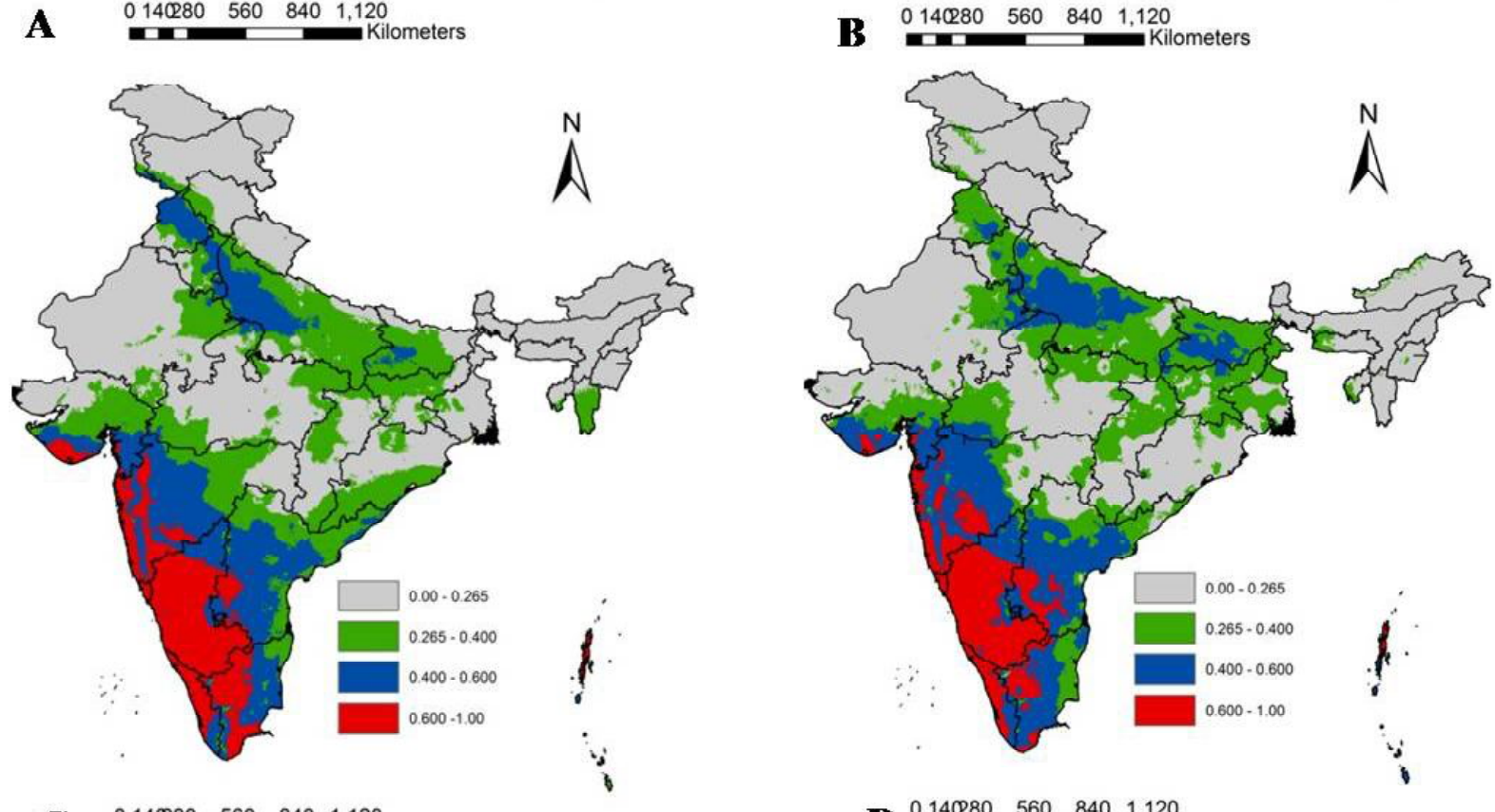

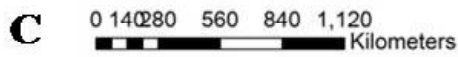

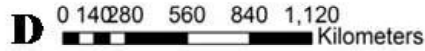

Fig. 5: Projected changes in distribution map of B. correcta in India during 2070, based on HADGEM2-AO GCM model among RCP 2.6 (A), RCP 4.5 (B), RCP 6.0 (C) and RCP 8.5 (D) climate scenarios.

resolution bioclimatic variables generated using recent climatic data, detailed knowledge host availability and soil data. Results from present study will be used by researchers, agriculture departments and policymakers for designing national-level $B$. correcta management strategies for horticulture crops.

\section{CONCLUSION}

Present study is the first attempt to agreement of $B$. correcta distribution and habitat suitability in India under changing climate scenarios using MaxEnt modeling based on occurrence data of species from different location. Our model projects a shift in distribution and suitability occur by the end of this century, currently no/low risk area of central India (Madhya Pradesh, Chhattisgarh and Jharkhand) and north-eastern India (Assam and Meghalaya) is likely to be moderately suitable for $B$. correcta. Primary maps generated in present study can also be useful for designing 
pest management strategies across India to mange and prevent expansion of species.

\section{ACKNOWLEDGMENT}

This work was supported by the Ministry of Agriculture, Government of India through the National Innovations in Climate Resilient Agriculture (NICRA) project under the Indian Council of Agricultural Research (ICAR) (ICAR-RCER/RCR/E.F./2011/29).

\section{REFERENCES}

Babu, K.S. and Viraktamath, S. (2003). Species diversity and population dynamics of fruit flies (Diptera: Tephritidae) on mango in northern Karnataka. Pestmanag. Economic Zool.,11: 103-110.

Berzitis, E.A., Minigan, J.N., Hallett, R.H. and Newman, J.A. (2014). Climate and host plant availability impact the future distribution of the bean leaf beetle (Cerotoma trifurcata). Glob. Chang. Biol., 20: 2778-2792.

Choudhary J.S., Rao M.S., Mali S.S., Das B., Kumari A., Mukherjee, D., Singh A.K. and Bhatt, B.P. (2017). Potential changes in number of generations of oriental fruit fly, Bactrocera dorsalis (Diptera: Tephritidae) on mango in India in response to climate change scenarios. J. Agrometeorol., 19(3): 200-206.

Dalal,P.K. and Arora, R. (2016). Impact of temperature on food consumption and nutritional indices of tomato fruit borer.J. Agrometeorol., 18(1): 62-67.

Drew, R.A.I. and Raghu, S. (2002). The fruit fly fauna (Diptera: Tephritidae: Dacinae) of the rainforest habitat of the Western Ghats, India. Raffles b. zool., 20:327-352.

Elith, J., Graham, C.H., Anderson, R.P., Dudik, M. and Ferrier, S. (2006). Novel methods improve prediction of species' distributions from occurrence data. Ecography, 29: 129-151.

Kapoor, V.C. (2002). "Proceedings of $6^{\text {th }}$ international fruit fly symposium 6-10 may 2002" Stellenbosch South Africa pp. 23-33.

Kumar, S. and Stohlgren, T. J. (2009). Maxent modeling for predicting suitable habitat for threatened and endangered tree Canacomyrica monticola in New Caledonia. $J$. Ecol. Nat. Environ., 1(4): 094-098.
Phillips, S.J., Anderson, R.P. and Schapire, R.E.(2006). Maximum entropy modeling of species geographic distributions. Ecol. Modell., 190: 231-259.

Ravikumar (2005). "Studies on fruit flies in guava and mango orchards with special reference to their management through mass trapping"M.Sc. (Agri) Thesis, University of Agricultural Sciences, Dharwad.

Sarada, G., Maheswari, T. U. and Purushotham, K. (2001). Seasonal incidence and population fluctuation of fruit flies in mango and guava. Indian J. Ent., 63:272-76.

Sharma, K., Sharma, R. K., Chander, S. and Jilu, V.(2015). Effects of weather parameters on guava fruit fly (Bactrocera zonata) populationat IARI, New Delhi.J.Agrometeorol., 17(2):227-229.

Singh, H. (2004). "Management of Bactrocera dorsalis(Hendel) in guava orchards and its impact on Dichocrosis punctiferalis Guenee.” Ph.D. dissertation, Punjab Agricultural University, Ludhiana, India.

Singh, S. and Sharma, D.R.(2013). Management of fruit flies in rainyseason guava through male annihilation technique using methyl eugenol based traps. Indian J. Horti., 70:512-18.

Sultana, S., Baumgartner, J. B., Dominiak, B. C., Royer, J.E. and Beaumont, L. J. (2017). Potential impacts of climate change on habitat suitability for the Queensland fruit fly. Sci. Rep., 7: 13025.

Vanitha, B.K., Bheemanna, M. and Prabhuraj, A. (2017). Diversity of fruit flies in different agro-climatic zones of Karnataka. J. Entomol Zool Stud., 5(6): 1163-1167.

Warren, D. L., Glor, R. E. and Turelli, M. (2010). ENMTools: a toolbox for comparative studies of environmental niche models. Ecography, 33: 607-611.

Warren,D.L. and Seifert, S.N.(2011).Ecological niche modeling in Maxent: the importance of model complexity and the performance of model selection criteria. Ecol. Appl., 21: $335-342$.

West, A. M., Kumar, S., Brownb, C.S., Stohlgren, T.J. and Bromberg, J. (2016). Field validation of an invasive species Maxent model. Ecol. Inform., 36: 126-134.

White, I.M. and Elson-Harris, M.M. (1992). "Fruit Flies of Economic Their Identification and Bionomics" CAB International, Wallingford Oxon, UK significance. 